\title{
A CONCEPÇÃO FREIREANA DE EDUCAÇÃO E O DIÁLOGO COM AS CULTURAS JUVENIS: CONHECER O JOVEM POR MEIO DA POESIA
}

\author{
Kelly da Silva Oliveira ${ }^{1}$, Márcia Regina Canhoto de Lima ${ }^{2}$, Joyce Cristina Claro Menotti ${ }^{3}$ \\ ${ }^{1}$ Mestra em Educação pela Universidade Estadual Paulista - UNESP, campus de Presidente Prudente, SP. Atua como \\ professora de Língua Portuguesa na Secretaria Estadual de Educação de São Paulo - SEESP. E-mail: \\ kellyletrasunesp@gmail.com \\ ${ }^{2}$ Livre Docente do Departamento de Educação Física e do Programa de Pós-Graduação em Educação da Universidade \\ Estadual Paulista - Unesp, campus de Presidente Prudente, SP. \\ ${ }^{3}$ Mestra em Educação pela Universidade Estadual Paulista - UNESP, campus de Presidente Prudente, SP.
}

\section{RESUMO}

Este artigo consiste em apresentar parte dos dados de uma pesquisa de Mestrado em Educação desenvolvida pela primeira autora deste texto que, na ocasião, foi professora dos jovens alunos, sujeitos da investigação. A pesquisa teve como fundamentação teórica estudos no campo da juventude e no campo da educação, com ênfase nas reflexões de Paulo Freire. A proposta objetivou ampliar as possibilidades de diálogo com as culturas juvenis nas aulas de língua portuguesa por meio da construção de textos poéticos. A metodologia escolhida é a pesquisa intervenção e os procedimentos de coleta de dados utilizados foram a observação, aplicação de formulários e entrevistas. Como resultados da pesquisa, destacam-se o estabelecimento de uma relação significativa com os jovens alunos, que se revelou a partir da partilha de anseios e de expectativas dos sujeitos pesquisados; a superação da insegurança dos jovens em escrever e, principalmente, em publicar os próprios escritos; a publicação do livro de poesias feito pelos jovens; a produção e publicação, no YouTube, de um vídeo "stop motion" de uma das poesias, extrapolando os muros da escola e, mais importante, a confirmação de que há caminhos (diversos) para o diálogo com as culturas juvenis. Nesse artigo, são apresentados os dados colhidos nas observações e nas entrevistas, que apontam que o diálogo proposto teve êxito e se revelou produtivo.

Palavras-chave: Paulo Freire. Ensino Médio. Culturas juvenis. Língua Portuguesa.

\section{THE FREIREANA CONCEPTION OF EDUCATION AND THE DIALOGUE WITH JUVENILE CULTURES: KNOWING THE YOUNGER THROUGH POETRY}

\begin{abstract}
This article consists of presenting part of the data of a Master's Degree in Education research developed by the first author of this text who, at the time, was a teacher of the young students, subjects of the investigation. The research was based on theoretical studies in the field of youth and in the field of education, with emphasis on the reflections of Paulo Freire. The purpose of this proposal was to expand the possibilities of dialogue with youth cultures in Portuguese Language classes through the construction of poetic texts. The methodology chosen is the intervention research and the data collection procedures used were the observation, application of forms and interviews. As results of the research, we highlight the establishment of a significant relationship with the young students, which was revealed from the sharing of the yearnings and expectations of the subjects surveyed; overcoming the insecurity of young people in writing and, especially, in publishing their own writings; the publication of the book of poetry by young people; the production and publication on YouTube of a "video stop-motion" of one of the poems, extrapolating the walls of the school and, more important, the confirmation that there are different ways to dialogue with youth cultures. In this paper, the data collected in the observations and in the interviews are presented, which indicate that the proposed dialogue was successful and proved to be productive.
\end{abstract}

Keywords: Paulo Freire. High School. Juvenile Cultures. Portuguese Language. 


\section{LA CONCEPCÍON DE EDUCACIÓN FREIREANA Y EL DIÁLOGO CON CULTURAS JUVENILES: CONOCER A LOS JÓVENES A TRAVÉS DE LA POESÍA}

\section{RESUMEN}

Este artículo consiste en presentar parte de los datos de una investigación de Maestría en Educación desarrollada por el primer autor de este texto que, en ese momento, era profesor de los jóvenes estudiantes, sujetos de la investigación. La investigación se basó en estudios teóricos en el campo de la juventud y en el campo de la educación, con énfasis en las reflexiones de Paulo Freire. El propósito de esta propuesta fue ampliar las posibilidades de diálogo con las culturas juveniles en las clases de lengua portuguesa a través de la construcción de textos poéticos. La metodología elegida es la investigación de intervención y los procedimientos de recolección de datos utilizados fueron la observación, la aplicación de formularios y las entrevistas. Como resultado de la investigación, tenemos: el establecimiento de una relación significativa con los jóvenes estudiantes, que se reveló al compartir los anhelos y expectativas de los sujetos encuestados; superar la inseguridad de los jóvenes por escrito y, especialmente, en la publicación de sus propios escritos; la publicación del libro de poesía por jóvenes; la producción y publicación en YouTube de un video "stop motion" de uno de los poemas, extrapolando las paredes de la escuela y, lo que es más importante, la confirmación de que existen diferentes formas de dialogar con las culturas juveniles. En este artículo, se presentan los datos recopilados en las observaciones y en las entrevistas, que indican que el diálogo propuesto fue exitoso y resultó ser productivo.

Palabras clave: Paulo Freire. La escuela secundaria. Culturas juveniles. Lengua portuguesa.

\section{INTRODUÇÃO}

$\mathrm{Na}$ contemporaneidade, muitas discussões relacionadas à juventude, principalmente as que se referem ao jovem estudante, alunos do Ensino Médio, tratam do desinteresse dos jovens pela escola. São inúmeras as suposições que surgem para explicar a "revolta" juvenil e, apesar de os estudos e de as pesquisas sobre a temática estarem ganhando espaço, ainda é comum a visão estereotipada sobre o jovem, atribuindo a eles os rótulos de rebeldes e/ou apáticos.

Estudar a categoria juventude é um processo que exige a compreensão de que não há apenas uma definição para ela, pois, diante de infinitas possibilidades de análise, de compreensão e de pontos de vista, pode-se notar que há "juventudes" e não juventude, elas são muitas, cada qual com sua particularidade. Portanto, faz-se necessário compreender, também, que não há somente uma cultura juvenil e, sim, culturas juvenis, com suas especificidades, suas histórias, seus contextos, suas necessidades, seus tempos e seus espaços diversos e diferentes. De acordo com Dayrell,

[...] os alunos já chegam à escola com um acúmulo de experiências vivenciadas em múltiplos espaços, através das quais podem elaborar uma cultura própria, uns "óculos" pelo qual veem, sentem e atribuem sentido e significado ao mundo, à realidade onde se inserem (DAYRELL, 1996, p.141).

Segundo o sociólogo Pais (2006, p. 7), "há duas diferentes maneiras de olharmos as culturas juvenis: através das socializações que as prescrevem ou das suas expressividades (performances) cotidianas". O autor (1990) compreende a juventude não como uma fase de transição, uma fase de vida em que as pessoas têm que necessariamente passar em todas as sociedades, mas usa o termo "curso de vida". Segundo Pais (2003), as diferentes formas de conceber a juventude são agrupadas de acordo com diferentes teorias, compreendidas em duas principais correntes que são: a geracional e a classista.

A primeira corrente aborda a juventude referida a uma fase da vida e a principal discussão refere-se à continuidade e à descontinuidade dos valores intrageracionais, "de acordo ainda com a corrente geracional, admite-se a existência de uma cultura juvenil que, de certa maneira se 
oporia à cultura de outras gerações (das gerações "adultas», mais concretamente)". Na segunda corrente, os jovens se relacionam segundo as classes sociais politicamente produzidas. As diferenças que se podem destacar nessa corrente são interpretadas como diferenças muito mais interclassistas - entre as classes diferentes - do que intraclassistas, de dentro da mesma classe.

Pais assume um posicionamento em relação às teorias da juventude, que é o das culturas juvenis, numa vertente antropológica das experiências cotidianas dos jovens. $\mathrm{O}$ autor entende esse conceito como:

$$
\begin{aligned}
& \text { [...] um conjunto de } \\
& \text { símbolos específicos que } \\
& \text { simbolizam a pertença a } \\
& \text { um determinado grupo; } \\
& \text { uma linguagem com seus } \\
& \text { específicos usos, } \\
& \text { particulares rituais e } \\
& \text { eventos, através dos quais } \\
& \text { a vida adquire um sentido. } \\
& \text { Esses "significados } \\
& \text { compartilhados" fazem } \\
& \text { parte de uum } \\
& \text { conhecimento comum, } \\
& \text { ordinário, cotidiano (PAIS, } \\
& \text { 2003, p. 70). }
\end{aligned}
$$

O autor esclarece, ainda, as culturas juvenis somente podem ser compreendidas se incorporadas à realidade social e destaca que é preciso superar modelos prescritivos que a sociedade impõe e dos quais os jovens não se enquadram mais. Diante dessa afirmação, é evidente que a escola não pode desconsiderar as práticas sociais e os modos de vida da juventude. Ao estabelecer práticas educativas rígidas, antidialógicas, verticais e autoritárias, os professores excluem, oprimem e distanciam, ainda mais, os jovens da escola.

Acredita-se que o respeito, o diálogo e a valorização das culturas dos jovens presentes na escola podem colaborar para um ensino mais significativo, promovendo uma educação conscientizadora, capaz de formar cidadãos críticos. Portanto, é preciso respeitar e considerar os saberes dos educandos, visto que são saberes socialmente construídos na prática comunitária.

A concepção de educação de Paulo Freire baseia-se na busca pela ação comprometida com a transformação da realidade, sempre priorizando o aluno como sujeito no seu processo de aprendizagem, concepção que vai ao encontro da Sociologia da Juventude, que fundamenta essa proposta de pesquisa. A democracia deve começar na escola, os alunos devem tomar consciência do seu lugar na sociedade - cidadãos de direitos e deveres - e na sua capacidade de interferir e modificar a sua realidade, e isso se dá por meio do diálogo em que todos tenham voz, como esclarece Carrano:

Percebidos como sujeitos de direito e de cultura, os jovens estudantes vão deixando de ser percebidos apenas como alunos e passam a ser enxergados a partir de identidades específicas que remetem ao sensível, ao corpóreo, à expressividade cultural e estética, e às sociabilidades que se originam no exterior da instituição escolar (CARRANO, 2009, p. 162).

Acolher as manifestações juvenis e valorizar suas culturas pode promover o diálogo entre professor e aluno e, posteriormente, o diálogo com a sociedade, formando cidadãos críticos capazes de interferir e modificar positivamente o mundo. É preciso quebrar as barreiras ainda existentes nas escolas e na sociedade em relação à juventude; desconstruir essa imagem negativa associada ao jovem como uma categoria problemática, rebelde, reduzindoa a entidade biológica. Além disso, é necessário reconhecê-los como sujeitos, como cidadãos participativos e ativos na sociedade, produtores de cultura, bem como transformadores da realidade.

Todo ensino de conteúdos demanda de quem se acha na posição de aprendiz que, a partir de certo momento, vá assumindo a autoria também do conhecimento do objeto. O professor autoritário, que recusa escutar os alunos, se fecha a esta aventura criadora. Nega a si mesmo a participação neste momento de boniteza singular: o da afirmação do educando como sujeito do conhecimento (FREIRE, 1997, p. 78). 
Há clareza de que não há práticas educativas "puras". É preciso que haja reflexão sobre a prática, a fim de que se possa atingir uma educação problematizadora. Há educadores que fazem a educação bancária de forma intencional e há outros que a fazem ingenuamente. 0 caminho é estudar, pesquisar, refletir, buscar quebrar preconceitos e barreiras que impedem a prática consciente e transformadora.

Certos de que a educação é uma arma poderosa, capaz de levar o homem à autonomia, cabe, pois, ao professor refletir e ter um olhar crítico voltado à própria prática, livre de julgamentos. Ao lidar com educandos, mais especificamente os jovens, os professores têm que ter essa consciência e cuidado, deve-se assumir uma postura ética, respeitar os valores do outro, integrá-lo ao processo educativo, não apenas como passivo receptor, mas como sujeito participativo, consciente e crítico.

$$
\begin{aligned}
& \text { Creio poder afirmar, na } \\
& \text { altura destas } \\
& \text { considerações, que toda } \\
& \text { práticaracativa } \\
& \text { demanda a existência de } \\
& \text { sujeitos, um que, } \\
& \text { ensinando, aprende, outro } \\
& \text { que, aprendendo, ensina, } \\
& \text { daí o seu cunho } \\
& \text { gnosiológico; a existência } \\
& \text { de objetos, conteúdos a } \\
& \text { serem ensinados e } \\
& \text { aprendidos; envolve o uso } \\
& \text { de métodos, de técnicas, } \\
& \text { de materiais; implica, em } \\
& \text { função de seu caráter } \\
& \text { diretivo, objetivo, sonhos, } \\
& \text { utopias, ideais. Daí a sua } \\
& \text { politicidade, qualidade } \\
& \text { que tem a prática } \\
& \text { educativa de ser política, } \\
& \text { de não poder ser neutra } \\
& \text { (FREIRE, 1997, p.41). }
\end{aligned}
$$

Em "Pedagogia do Oprimido", Paulo Freire trouxe a concepção de educação bancária esclarecendo como esta funciona como instrumento de opressão, excluindo os educandos da sociedade - oprimidos:

$$
\begin{aligned}
& \text { Na visão "bancária" da } \\
& \text { educação, o "saber" é uma } \\
& \text { doação dos que se julgam } \\
& \text { sábios aos que julgam } \\
& \text { nada saber. Doação que se } \\
& \text { funda numa das } \\
& \text { manifestações } \\
& \text { instrumentais da ideologia }
\end{aligned}
$$

da opressão - $\quad$ a

absolutização da ignorância, que constitui o que chamamos de alienação da ignorância, segundo a qual esta se encontra sempre no outro (FREIRE, 1983, p. 33).

Conscientes de que a finalidade da educação não é apenas formar profissionais ou alunos com excelentes notas, mas, sim, formar pessoas, sujeitos autônomos e capazes de se posicionarem na sociedade como cidadãos atuantes, fundamentou-se essa pesquisa no referencial teórico da Sociologia da Juventude e nos pressupostos freireanos $e$, dentre os caminhos pesquisados para estabelecer o diálogo entre os conteúdos sistematizados e as culturas juvenis, destaca-se, nesse artigo, o caminho da poesia como uma ponte entre as manifestações juvenis e as aulas de língua portuguesa.

Para a realização da pesquisa foi necessário compreender de que forma a escola auxilia o jovem no processo de socialização, no seu processo de construção de identidade e de emancipação humana e como tal instituição considera ou não as manifestações juvenis. Nesta direção, Juarez Dayrell (2007, p.1107) aponta que “[...] a escola 'faz' a juventude, privilegiando a reflexão sobre as tensões e ambiguidades vivenciadas pelo jovem, ao se constituir como aluno num cotidiano escolar que não leva em conta a sua condição juvenil”.

Assim como destaca Dayrell, a escola não pode mais desconsiderar tais tensões juvenis, afinal, para que o conhecimento seja de fato significativo, como esclarece Paulo Freire (1997), é preciso romper com a dicotomia "educadores $\mathrm{X}$ educandos", acabar com essa distância, superar a relação vertical existente. Não há ato educativo sem respeito.

Uma das tarefas mais importantes da prática educativo-crítica é propiciar as condições em que os educandos em relação uns com os outros e todos com o professor ou a professora ensaiam a experiência profunda de assumir-se. Assumir-se como ser social e histórico, como ser pensante, comunicante, transformador, criador, 
realizador de sonhos, capaz de ter raiva porque capaz de amar. Assumir-se como sujeito porque capaz de reconhecer-se como objeto (FREIRE, 1997, p.23).

Se o jovem não vê significado algum em estudar, em estar na escola, é responsabilidade de toda a sociedade, resgatá-lo. Os jovens alunos precisam de apoio, de uma educação que os oriente para a vida, não se limitando ao mercado de trabalho ou para a escolha profissional.

o professor que desrespeita a curiosidade do educando, o seu gosto estético, a sua inquietude, a sua linguagem, mais precisamente, a sua sintaxe e a sua prosódia; o professor que ironiza o aluno, que minimiza, que manda que "ele se ponha em seu lugar" ao mais tênue sinal de sua rebeldia legitima, tanto quanto o professor que se exige do cumprimento de seu dever de ensinar, de estar respeitosamente presente à experiência formadora do educando, transgride os princípios fundamentalmente éticos de nossa existência (FREIRE, 1997, p.35).

A prática educativa exige posicionamento diante da sociedade e um fazer ético e consciente. Ao criar a proposta de pesquisa valorizar as manifestações juvenis para ressignificar positivamente as aulas de língua portuguesa - levou-se em consideração à condição do jovem hoje nas escolas públicas de Ensino Médio, suas opiniões, suas possibilidades e suas culturas particulares. A proposta centrouse em oferecer contribuições para ampliar a compreensão sobre a necessidade de as escolas estabelecerem relações mais significativas com os jovens alunos do Ensino Médio, conhecendo verdadeiramente quais são seus anseios, suas expectativas, suas dúvidas e seus desejos.

Os objetivos dessa pesquisa foram: identificar quais eram as manifestações juvenis dos sujeitos da pesquisa e analisar de que forma a disciplina de Língua Portuguesa poderia realizar um diálogo integrativo com as culturas juvenis, garantido a apropriação dos conteúdos sistematizados.

\section{METODOLOGIA}

Investigaram-se os alunos conciliando vida acadêmica e vida profissional, a primeira autora do artigo foi professora efetiva em uma escola pública da Diretoria de Ensino de Presidente Prudente/SP e essa pesquisa foi realizada no período de um ano letivo, na referida instituição, e os sujeitos foram os alunos de uma turma do primeiro ano do Ensino Médio.

A natureza da pesquisa é a abordagem qualitativa, caracterizando-se como pesquisaintervenção, realizando-se uma análise interpretativa e crítica do material coletado (ALVES, 1991). As generalizações do tipo estatístico foram feitas somente com algumas perguntas dos questionários. Essa metodologia permitiu compreender os fenômenos juvenis a partir da perspectiva de alguns dos participantes das intervenções, obtendo dados descritivos que só poderiam ser alcançados devido à interação entre pesquisador com a situação objeto de pesquisa.

A pesquisa-intervenção foi escolhida, em função de garantir a indissociabilidade entre a produção de conhecimento e a transformação da realidade investigada, vindo ao encontro à abordagem qualitativa. Por ser sempre participativa e ter uma relação próxima, dialógica e interativa entre pesquisador e jovens alunos, a pesquisa possibilitou de fato realizar um diálogo entre as culturas juvenis e as aulas de Língua Portuguesa. Afinal, "configurar um campo de investigação em que o pesquisado tem voz e se apresenta como um agente social e individual transforma essencialmente a prática da pesquisa" (PORTUGAL, 2008, p.18). A pesquisa intervenção:

[...] não se constitui como uma tecnologia derivada de um conhecimento purificado a ser aplicado sobre um objeto que se quer aprimorar ou que sofreu algum desvio de sua forma padrão, mas como uma opção política diante das formas de dominação em que há participação de práticas acadêmicas (PORTUGAL, 2008, p. 18). 
Esse tipo de pesquisa, intervenção, exige mais do que aproximação entre pesquisador e objeto de pesquisa, exige o estabelecimento de um vínculo. Gonsalves (2011) discorre sobre o "distanciamento" no trabalho científico destacando que a aproximação entre pesquisador e objeto de pesquisa não compromete o olhar crítico sobre a pesquisa. Segundo a autora, há três pontos importantes e que devem ser considerados, são eles: a possibilidade de compreender a partir do envolvimento, a relação sujeito-objeto do conhecimento e a questão da afetividade do conhecimento. Os três pontos destacados serviram de base para a metodologia escolhida para essa pesquisa, visto que "a subjetividade é, ela mesma, condição para o exercício da investigação científica" (GONSALVES, p.22, 2011).

As técnicas selecionadas para a coleta de dados dessa pesquisa foram: observação participante, registros em diário de campo e a aplicação de formulários e de entrevistas. As aulas/intervenções aconteceram no ano de 2016 no período matutino, junto à disciplina de Língua Portuguesa - cinco aulas semanais de 50 minutos cada. As entrevistas reflexivas possibilitaram a obtenção de dados descritivos que foram alcançados devido à interação com os jovens alunos. Vale apontar que a pesquisa seguiu todos os requisitos éticos. $O$ número do comitê de ética é 66762917.7.0000.5402. Termos de Consentimento Livre e Esclarecido (TCLEs) foram assinados pelos responsáveis, já os Termos de Assentimentos foram assinados pelos jovens pesquisados.

\section{RESULTADOS E DISCUSSÃO}

Nesse artigo, será conferida ênfase para uma das atividades propostas que permitiu o diálogo com as culturas juvenis: a construção de textos poéticos. Dentre os procedimentos utilizados para a coleta de dados, destacam-se algumas observações e a fala de um dos jovens entrevistados a respeito das aulas de construção de texto poético, a fim de explanar sobre a importância de estar atento ao cotidiano do aluno e de compreender e conhecer a sua realidade.

Teve-se o lançamento do primeiro livro de poesias feitas pelos alunos. As poesias da turma da manhã foram feitas durante as aulas. Algumas são reveladoras, trazem questionamentos dos jovens em relação à vida, ao amor, ao preconceito e à construção de identidade. Assim como propõe Paulo Freire e os estudiosos no campo da juventude, é de extrema importância conhecer o aluno e suas realidades, bem como estar atentos aos apelos que são verbalizados ou não durante as aulas/intervenções.

O exercício de se colocar para o mundo por meio da linguagem é algo que exige coragem, esforço e vontade. Esse projeto da escola foi bem acolhido pelos jovens alunos, mesmo aqueles que se demonstraram resistentes de início. As poesias foram selecionadas pela equipe de professores, os alunos demonstraram alegria em participar desse processo.

A capa do livro foi feita por uma aluna e há, no livro, poemas e ilustrações feitas pelos alunos da escola toda. Segue, abaixo, algumas poesias que revelam como se sentem os jovens alunos.

\section{Agonia}

No mundo em que vivemos hoje em dia A sociedade piora dia-a-dia

Pessoas morrem todos os dias.

Uns sofrem pela cor

Outros rejeitados pela família

E outros que caíram no mundo das drogas Cada um com sua agonia.

\section{Minha lucidez}

Eu poderia falar sobre várias coisas Mas escolhi falar sobre personalidade É algo polêmico porque ninguém aceita a verdade.
"Ser igual a todos
É medo de se mostrar
Como realmente é"

Eu roubei isso do site de uma mulher.

Em poucas palavras

Ela disse tudo e muito mais

$\mathrm{E}$ isso me completa,

Me satisfaz.

Importar-se pra quê?

Os outros vão falar

É perda de tempo

Tristeza no olhar.

Sou louca, sim!

O mundo não merece minha lucidez

Seja quem você é, 
E se assume de uma vez!

\section{Escuros e claros}

Tu dizes que somos iguais Somos únicos aos olhos de Deus Mas essa mentira não me vais mais, Pois somos diferentes aos olhos teus.

Se é a minha cor escura, digas Se é a minha fala dura, gritas Se é de onde vim, me contas Mas não minta pra mim, não me dê as costas.

Sua religião só Ihe prega a igualdade Mas o seu interior discorda

Pois para a sua verdade

Escuros e claros não puxam a mesma corda.

\section{Roupa não define caráter}

Nós mulheres ouvimos

Tanto por aí

Anda de short curto

Pra chamar atenção dos guris.

Quando uma mulher é abusada

Todos julgam pela capa

Mas mulher nenhuma

Deve ser violentada.

Nesse mundo preconceituoso Quando a mulher é violentada

A culpa ainda é da vítima

Que usa roupa descolada.

Enfim, nada justifica

A violência contra a mulher Independente de roupa e de tudo Mulher deve ser respeitada.

\section{O jardim}

Talvez eu seja apenas um garotinho

Perdido em um mundo de deuses e monstros

Sozinho em um jardim escuro e frio Cheio de rosas e espinhos

Um túnel me aguarda, onde uma luz brilhava Sobre a noite pálida e sensata

Que sempre dava lugar ao sol da manhã

Talvez eu ainda seja apenas um garotinho
Que perdeu seu maior medo

O medo de se estar sozinho

Em um jardim escuro e frio.

Podemos perceber que, por meio da poesia, os jovens alunos fizeram suas denúncias, questionaram, tocaram em assuntos que consideravam importantes e, dessa forma, mostraram aos outros sua visão de mundo.

Os estilos e culturas juvenis são as formas pelas quais vai-se configurando a experiência da condição juvenil. Os sujeitos jovens procuram ingressar na esfera pública de diversas formas (através da música, do trabalho, das expressões culturais, etc.), construindo formas próprias de sociabilidade, exercitando a convivência social e o contraditório espaço das diferenças (BARBIANI, 2007, p. 147).

A última poesia, "o jardim", feita pelo aluno Felipe ${ }^{1}$, foi transformada por ele em um "stop motion". Ele surpreendeu a todos, tanto com sua poesia como com a produção do "stop motion". No arquivo de vídeo ele conta, por meio do seu poema, como se sente em relação ao mundo. Foi uma grata surpresa. Ele conseguiu se expressar por meio desse vídeo revelando uma parte de sua cultura e unindo a tecnologia à literatura.

A poesia "minha lucidez" foi escrita pela aluna Valentina, essa jovem passou por uma mudança interna que foi refletida nas suas vestimentas, nos seus cabelos e no seu jeito de agir. Passou de cabelo longo e liso para um cabelo curtíssimo e naturalmente cacheado. Deixou de falar tão pouco, passou a se colocar mais nas discussões em sala, ainda com cautela e sempre muito racional. Escreveu uma das poesias mais lindas da escola, revelou a sua transformação ali. Sobre esse fato, a aluna declarou: "Acho que a pessoa se expressa, né. Quando você gosta de escrever, gosta de se expressar, acho que a poesia é um bom caminho".

O trabalho realizado com os sujeitos escolhidos foi intenso. A construção do texto

\footnotetext{
${ }^{1}$ Todos os nomes utilizados nessa pesquisa são fictícios.
} 
poético foi um dos caminhos propostos para estabelecer o diálogo com os jovens e, por meio de uma educação problematizadora que reconhece o aluno como sujeito e protagonista do seu aprendizado.

A criação do livro de poesias não foi um trabalho de fácil execução. A autoestima dos alunos foi o alvo principal desde o início. Muitos se negaram a participar, afirmavam que não sabiam escrever poesia e que não entendiam quando liam os textos desse gênero. Ao longo das aulas, desconstruiu-se essa ideia de que a poesia é algo distante da realidade deles e, com o passar das intervenções, eles se permitiram tentar.

A cada aula, um aluno trazia um texto, pediam que a professora lesse, faziam algumas pequenas alterações, mas, sempre, deixando claro que os textos deveriam revelar o que eles eram ou pensavam. Foi preciso explicar que não é necessário encaixar-se em modelos de escrita, mas, sim, permitir que as reflexões que eles faziam verbalmente poderiam ser colocadas em formato de poesia. E, assim, aconteceu. As poesias refletem $O$ que pensam os jovens pesquisados, suas inquietações e sua coragem em se colocar para o mundo.

Com o aprofundamento de leituras no campo da Educação e da Sociologia da Juventude, vislumbrou-se uma possibilidade de diálogo entre o jovem e a escola. Tais leituras revelaram a necessidade de a escola considerar e valorizar as múltiplas culturas existentes em seu espaço, um local em que os alunos queiram estar. Por meio do conhecimento e da valorização das culturas juvenis, seria possível ressignificar o processo de ensino de ensino-aprendizagem e, com isso, tornar as aulas interessantes para os jovens alunos. (SPÓSITO, 1993, 1997; ABRAMO, 1994, 1997; DAYRELL, 1996, 2007; PAIS, 1990, 2003, 2006; CARRANO, 2009, 2011; MELUCCI, 2007; PERALVA 2007).

\section{CONCLUSÃO}

Quanto ao diálogo entre as culturas juvenis e a aulas, que, no caso, eram de Língua Portuguesa, não só é possível, mas urgente. As manifestações culturais juvenis quando incorporadas ao ensino dos conteúdos sistematizados enriquecem o processo educativo, e essa ação pode ressignificar esse momento da vida estudantil dos jovens. É necessário assumir uma postura de valorização das culturas juvenis diante do contexto escolar.
A escola que acolhe o jovem, que o ouve, e o compreende estabelece uma relação de confiança e esse tipo de vínculo, além de ser enriquecedor para o processo educativo, gera bons frutos para a escola do Ensino Médio como, por exemplo, a diminuição da taxa de abandono e a ressignificação dessa etapa do ensino.

A professora da turma pôde perceber que realizar esse diálogo ressignificou também a sua práxis. Compreender as expressividades dos jovens é assumir que o diálogo com as culturas juvenis não é um conjunto de técnicas a serem aplicadas em sala de aula para entreter ou conquistar os alunos. É, sim, um caminho para conhecê-los, um meio de respeitá-los, de ouvi-los e, com isso, possibilitar a eles novas perspectivas de vida. Por ser um processo único, cada realidade trará ao ambiente escolar manifestações diversas, não é possível controlalas, mas é possível olhar para elas sem preconceitos. Essa proposta que pode contribuir para mudar o cenário atual do Ensino Médio e dar sentido ao processo de escolarização para os jovens.

A proposta de valorizar as culturas juvenis em sala de aula ainda sofre críticas por ser confundida com momentos de descontração, contudo, essa compreensão está equivocada. O fato de valorizar as culturas juvenis em sala de aula não se trata de agradar ao jovem, nem de negligenciar os conteúdos sistematizados, é necessário entender primeiro que suas culturas são como um ponto de partida para aprofundar e ressignificar as aulas e alguns conteúdos sistematizados que compõem o Currículo. A proposta faz referência, portanto, ao ato de contemplar, durante o processo de ensinoaprendizagem, as manifestações e os anseios do jovem para que o ensino seja significativo, contextualizado, interessante e desejado.

Para demonstrar os resultados da pesquisa foram selecionados alguns fatos considerados mais importantes para a efetivação do diálogo entre as culturas juvenis e as aulas, alguns dados dos formulários, alguns trechos das entrevistas e alguns apontamentos feitos pelos próprios jovens alunos, seja por meio de questionamento ou por meio de produção escrita.

A pesquisa comprovou que é possível abordar os anseios juvenis sem deixar de garantir a apropriação dos conteúdos sistematizados. Os caminhos são muitos. Nesta pesquisa elencaram- 
se alguns deles, não com a intenção de elaborar receitas, mas, sim, de apontar propostas.

Realizar essa conexão gerou frutos não apenas nas aulas em que os jovens percebiam que estávamos discutindo assuntos dos seus interesses, mas em outras de assuntos adjacentes e diferentes, pois compreenderam a importância da autoria deles no estudo dos conteúdos escolares.

Mais do que aceitar responder formulários ou participar de entrevistas, os alunos aceitaram dividir seus anseios e perceber que por meio da relação de cumplicidade, surgiu o diálogo entre as suas culturas e as aulas.

\section{REFERÊNCIAS}

ABRAMO, H. Cenas Juvenis. São Paulo, Página Aberta Ltda., 1994.

ABRAMO, $H$. Considerações sobre a tematização social da juventude no Brasil. Revista Brasileira de Educação. São Paulo: ANPED, número especial. № 5-6, 1997.

ALVES, A. J. O planejamento de pesquisas qualitativas em educação. Cadernos de Pesquisa, v.77, p. 53-61, mai. 1991.

BARBIANI, R. Mapeando o discurso teórico latinoamericano sobre juventude(s): a unidade na diversidade. Revista Textos \& Contextos, v. 6, n. 1, p. 138 - 153, jan./jun. 2007.

CARRANO, P. Identidades culturais juvenis e escolas: arenas de conflitos e possibilidades. Diversia. Educación y Sociedad, v. 1, p. 159-184, abr. 2009.

CARRANO, P.; MARTINS, C. A escola diante das culturas juvenis: reconhecer para dialogar. In: Educação, Santa Maria, v. 36, n. 1, p. 43-56, jan./abr. 2011.

DAYRELL, J. A escola como espaço sócio-cultural. In: DAYRELL, Juarez (Org.). Múltiplos olhares sobre educação e cultura. Belo Horizonte: Ed. UFMG, 1996. p.137-161.

DAYRELL, J. “A escola 'faz' as juventudes? Reflexões em torno da socialização juvenil”. Educação e Sociedade, Campinas, v.28, n.100, p.
1105-1128, out. 2007.

https://doi.org/10.1590/S0101733020070003000

$\underline{22}$

FREIRE, P. Pedagogia do Oprimido. 12 ed. Rio de Janeiro: Paz e Terra. 1983.

FREIRE, P. Pedagogia da Autonomia: Saberes necessários à prática educativa. Rio de Janeiro: Paz e Terra, 1997.

GONSALVES, E. P. Iniciação à pesquisa científica. 3 ed. Campinas: Alínea, 2003.

MELUCCI, A. Juventude, tempo e movimentos sociais. In: FÁVERO, O.; SPÓSITO, M.; CARRANO, $P$.; NOVAES, R. Juventude e Contemporaneidade. - Brasília: UNESCO, MEC, ANPED, 2007, p. 29 46.

PAIS, J. M. A construção sociológica da juventude-alguns contributos. Análise Social, v. 25, p. $139-165,1990$.

PAIS, J. M. Culturas Juvenis. Lisboa: Imprensa Nacional casa da Moeda, 2003.

PAIS, J. M. Buscas de si: expressividades e identidades juvenis. In: ALMEIDA, M.; EUGENIO, F. Culturas Jovens: novos mapas do afeto. Rio de Janeiro: Jorge Zahar Editor, 2006. p. ?-?.

PERALVA, A. O jovem como modelo cultural. In: FÁVERO, O.; SPÓSITO, M.; CARRANO, P.; NOVAES, R. Juventude e Contemporaneidade. - Brasília: UNESCO, MEC, ANPED, 2007, p. 13-28.

PORTUGAL, F. T. A pesquisa-intervenção e o diálogo com os agentes sociais. In: CASTRO L. R.; BESSET V. L. (Orgs). Pesquisa-intervenção na infância e juventude. Rio de Janeiro: Nau editora, 2008. p. ?-?.

SPOSITO, M. P. A sociabilidade juvenil e a rua: novos conflitos e ação coletiva na cidade. Tempo Social; Rev. Sociol. USP, S. Paulo, p.161-178, 1993.

SPOSITO, M. P. Estudos sobre juventude em educação. Revista Brasileira de Educação; Mai/Jun/Jul/Ago; n.5, Set/Out/Nov/Dez; n.6, p. $37-52,1997$. 